
century, there has been a substantial increase in the area of cropland in the of urban settlements and irrigated agalbedo; 2) Changing the surface evapowave resilience, vulnerability to floods models show varying results of the net the surface. This has possibly led to a
Historic changes in land use have cantly. For example, since the signifimiddle latitudes of the Northern Hemisphere. The pronounced tropical deforestation during the $20^{\text {th }}$ century has paralleled the large-scale development riculture. The land-cover changes have resulted in a number of alterations in the regional and global climate system primarily by: 1) Changing the surface transpiration; 3) Modifying winds, heat and other such factors in the proximity of human settlements; and 4) Modifying atmospheric $\mathrm{CO}_{2}$ uptake.

Changes in the albedo and evaporation have likely had a discernible effect on global mean temperatures since the late $19^{\text {th }}$ century, although effects on climate (Pitman et al. 2009). Decreased forest cover has generally increased the surface albedo, thereby reducing the net energy available at downward modulation of the global $0.7^{\circ} \mathrm{C}$ since instrumental measurements began; IPCC 2007) by $0-0.1^{\circ} \mathrm{C}$ (de No-

blet-Ducoudré et al., in press). Local and-atmosphere feedbacks generate large spatial variability of the land-us temperature changes are relatively small in the tropics, but increase significantly while moving to the equator. In likely more than compensated for the global mean warming induced by elevated greenhouse gas concentrations (de Noblet-Ducoudré et al., in press; Fig. 1), although this finding needs to be balanced with the fact that deforestation itself has significantly contributed to the increase in $\mathrm{CO}_{2}$ (Pongratz et a. 2010). Net effects of land use on evaporation are more uncertain than those on albedo. Higher evaporation may be alternatively found over forests or grassland depending on the local conditions (Teuling et al. 2010).

Apart from the direct impacts on the physical climate system, large-scale deforestation has resulted in a sigificant release of carbon to the atmocaused by fossil fuel burning. On top of the estimated $9.1 \pm 0.5 \mathrm{Gt}$ carbon reeased from fossil resources in 2010, an released by land-use change (Peters al. 2011). Through the combination of

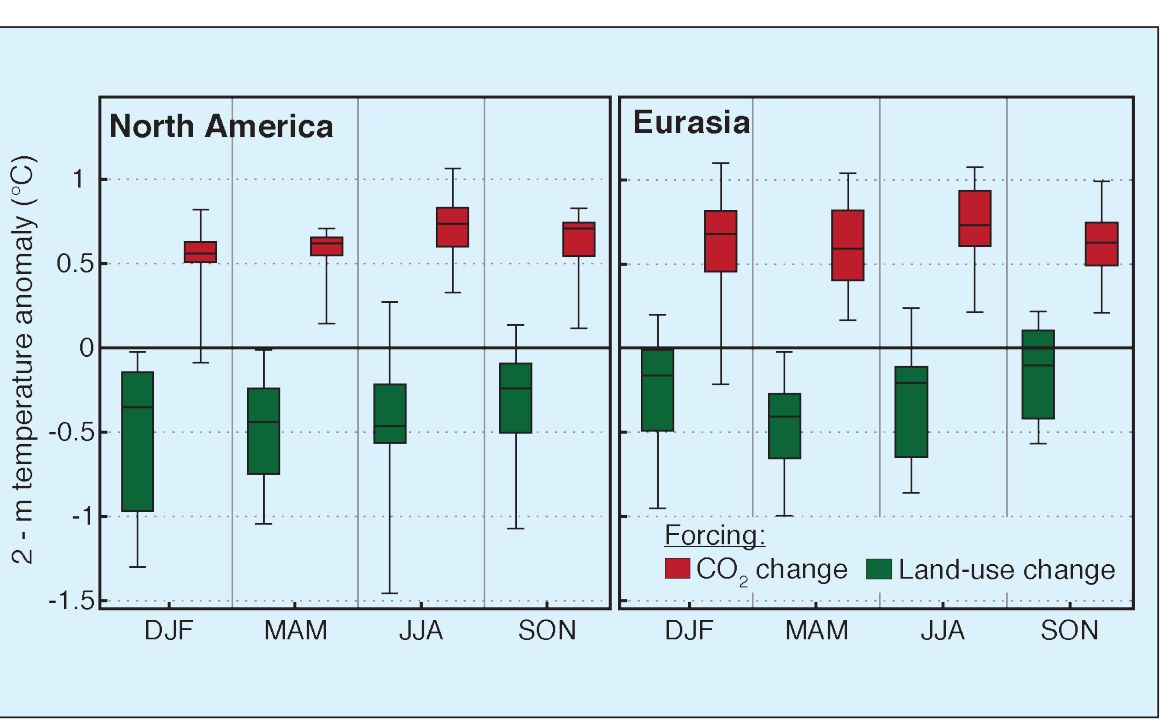

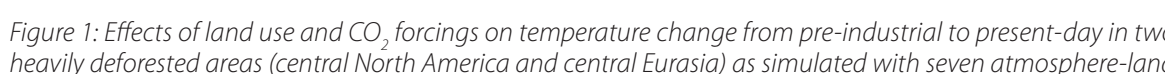

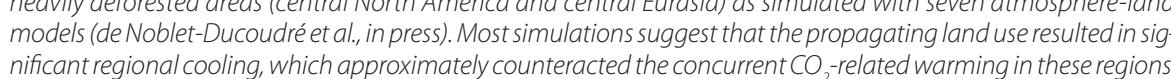
areas with large deforestation (e.g.USA central Eurasia) the local cooling has sphere, adding to the $\mathrm{CO}_{2}$-perturbation
$\mathrm{CO}_{2}$ and biophysical effects, deforestation is expected to lead to a net climate warming in tropical regions, but possibly to a net cooling in boreal regions (Betts et al. 2007, Bonan 2008). However, human management could also play a role, because areas that are deforested tend to have higher carbon content and less snow cover (Pongratz et al. 2011). Another marked effect of land-use change on climate is an increase in vulnerability to climate extremes, both because of the potential inability of forest areas to dampen temperature extremes during the early heatwave stages, and because of the increased exposure to extreme events like floods.

In the context of the $5^{\text {th }}$ Coupled Model Intercomparison Project (CMIP5), many Global Circulation Model projections have been carried out for a number of future socio-economic scenarios, including land-use change. Early results indicate that the overall magnitude of projected land-use change (that is, the conversion of natural vegetation to cropland) is generally smaller than observed during the $20^{\text {th }}$ century in all future scenarios. The regional differences, however, are pronounced. Sub-Saharan Africa is projected to experience a sigAficant increase in agricultural area in most of the scenarios, even in the lowmission scenario targeted to meet the degree global warming criterion. The local expression with climate and the large spatial variability of the nature and degree of landuse change calls for an increasing fochange at a regional level.

\section{Selected references}

fur reterente listoninineunder.

Bonan GB (2008) Isience 320: 1444

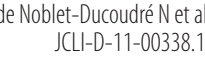

Peters GP P tal. (2011) Nature Climate Change 2: 2-4
Pitman AJ tal. (2009) Geophysical Researh Letters 36 ,

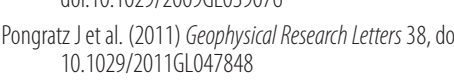

During the 12,000 years preceding the sheets, stabilizing sea level, and changes in temperature and precipitation patterns influenced global land cover Over the same period humans adopted agriculture domesticated animals, developed metallurgy and other technologies, and evolved in their social and cultural systems. These changes led to exponential growth in human populations, urbanization, and the expansion of human settlements to the man-induced and natural environmental change over the Holocene resulted in the transformation of the Earth's system by modifying land cover and through emissions of greenhouse gases and aerosols. Preindustrial anthropogenic activities, mainly deforestation, rice cultivation, and domestication of ruminants, resulted in substantial emissions of $\mathrm{CO}_{2}$ and $\mathrm{CH}_{4}$ to the atmosphere. This change in greenhouse gas concentrations could have affected global climate to the point of precluding the inception of a new glacial period (Ruddiman 2003; Ruddiman et al. 2011). Ruddiman based his analysis on orbital forcing, thought to be the ultimate cause of ice age inception, and

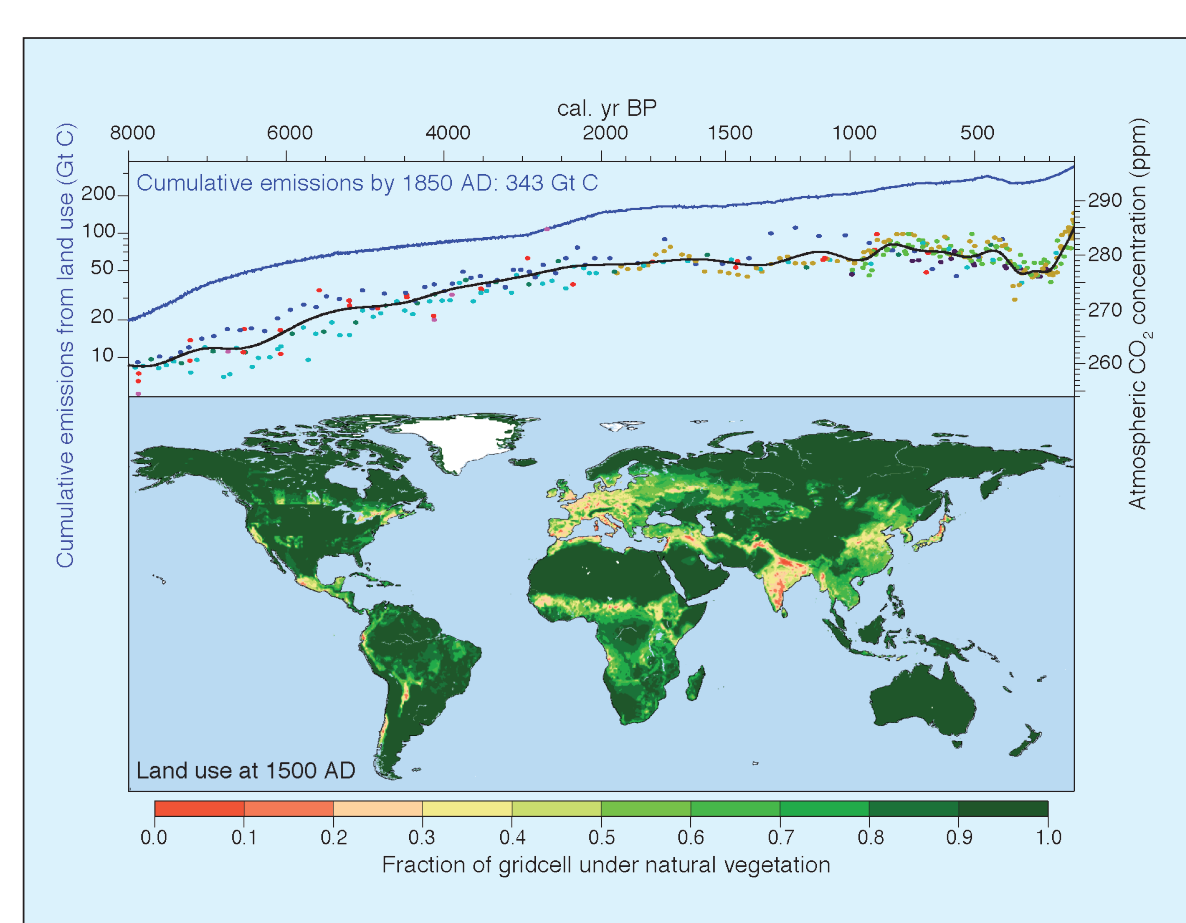

Figure 1: Top: Preindustrial Holocene atmospheric CO, concentrations measured in Antarcticicic cores (dots, black
line), and carbon emissions as a result of anthropogenic land cover change (blue line). Bottom: Global land use

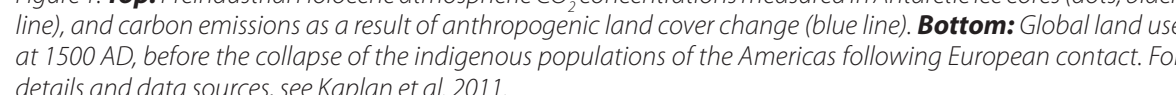

tmospheric $\mathrm{CO}_{2}$ and $\mathrm{CH}_{4}$ concentrations measured in ice cores. He concluded tha locene showed anomalous trends when compared to previous interglacials. Ruddiman's analysis has been criticized on and greenhouse gas records, and because most previous interglacials show a time trend in orbital forcing that is not completely analogous to the Holocene. There different from the rest of Earth history: the The of behaviorally modern humans. mans probably had on large-scale land cover is the application of fire for the improvement of hunting and gathering opportunities. Even extremely low populacover using fire (Bowman 1998; McWethy genic trend is not identified in synthesis of charcoal records from sedimentary archives (Marlon et al. 2008) this may be result of the fact that we have no appropriate baseline without human influence h which to assess the data, e.g. from entire ice-free area of the world. Both hu-
With the Neolithic revolution, the human however, that we know makes this epoch and increases in aerosols ing could have occurred as a result of increased surface and atmospheric albedo, have shown that these effects are limited to the region where land cover change occurred. Furthermore, preindustrial human activities affected the global hydrological balance: deforestation leads to reductions runoff; these alterations could also have led to seasonally contrasting changes in regional climate. Anthropogenic activities probably had an influence on regional and
global climate over the Holocene, long before the Industrial Revolution.

Selected references Full leferencel lit online under?

FullerDQ etal. (2011) The Hoblecere 21 (15): 743-759

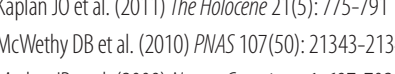

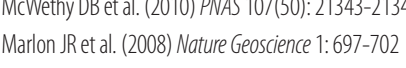

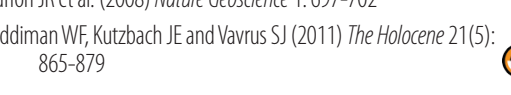
tal. 2009). Where an obvious anthropo- 